\title{
Professor Juan Carlos Casanova has passed away
}

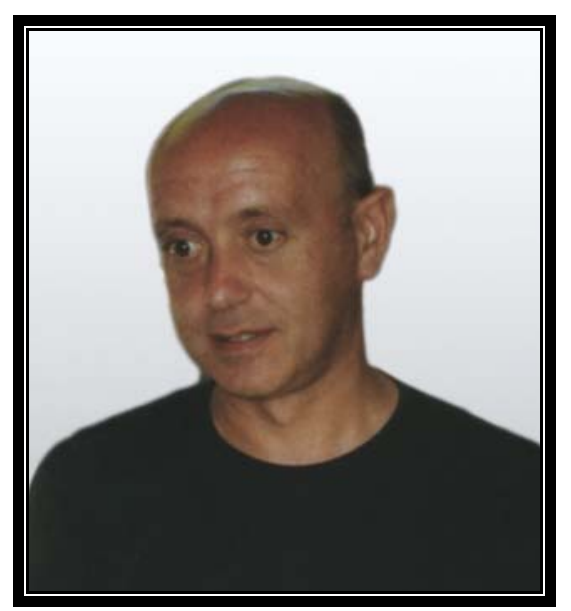

The parasitological community has recently received a startling and sad announcement about a death of Professor Juan Carlos Casanova i García, PhD. who passed away on January $18^{\text {th }}, 2013$, shortly before his $50^{\text {th }}$ birthday. An internationally known parasitologist was born on August $11^{\text {th }}, 1963$ in Sant Julià de Cerdanyola, Catalonia, Spain. He completed undergraduate studies at the Faculty of Farmacy, University of Barcelona, Spain, in 1989, with his diploma project focusing on helminth fauna of the wildcat (Felis silvestris) in the Iberian Peninsula. After completion of his studies, he was employed at the Department of Health Microbiology and Parasitology of his mother University, where he remained throughout his life. His professional career was directed to the field of helminthology in 1993, he was awarded the PhD. degree having successfully defended his thesis "Ecological analysis of the helminth fauna of wild mammals" under supervision of Prof. Carlos Feliu and Prof. Jordi Torres, and he was awarded Professor in 1997.

The scientific degrees were accompanied by teaching career and both science and education represented parallels of his life. From 1989, he published 8 textbooks, 68 indexed papers, 21 other scientific works, and more than 110 conference contributions. It seems that the breakthrough moment in his scientific rise occurred in 1995 when he participated at the $7^{\text {th }}$ International Helminthological Symposium held in Košice, Slovakia, where he personally acquainted with Slovak helminthology nestor, Ing. Jozef K. Macko. Young Juan Carlos started to collaborate directly with his team, coming back to Košice in two months' time. From that moment, a fruitful cooperation in taxonomy, systematics, and karyology of helminths lasted for decades resulting in many joint publications and mutual visits of members of both research teams.

In truth, scientific pilgrimage of Prof. Casanova was characterized by his broad research contacts and close collaborations also with Spanish, French and Italian parasitologists from the Faculty of Pharmacy of the University of La Laguna, Canary Islands, the Faculty of Veterinary Science of the University of León, the Faculty of Veterinary Science of the University of Santiago de Compostela, the Agricultural Experimental Station in León and the Doñana Biological Station in Sevilla of the Spanish Council for Scientific Research CSIC (Spain), the Laboratory of Tropical and Mediterranean Ecology of the University of Perpignan (France), and the Department of Ecology of the University of Calabria (Italy), and all the cooperation included joint fieldworks and exchange visits. He co-operated on 14 research projects and lectured on parasitology not only at the University of Barcelona but also at the above mentioned academes, where supervised or co-supervised PhD. students Xavier Molina, Pilar Foronda, Concetta Milazzo and Alexis Ribas.

He was driven by his love for science and helminthology in particular, exuding enthusiasm, tenacity and helpfulness. His scientific profile included number of theoretical and practical problems relating to the systematics, taxonomy and ecology of helminth parasites of mammals, and he originally described 9 helminth species new for science.

We are all well aware of the fact that human life and nature are incomparably richer and can not be described in a few lines. As the long-time collaborators and friends, we are certain that the work and charisma of Prof. Casanova will never be forgotten.

Marta Špakulová, Carlos Feliu José, and Alexis Ribas Salvador 